\title{
An Introduction to Biochars and Their Uses in Agriculture ${ }^{1}$
}

\author{
Rao Mylavarapu, Vimala Nair, and Kelly Morgan²
}

Biochar, also known as black carbon, is a product derived from organic materials rich in carbon $(\mathrm{C})$ and is found in soils in very stable solid forms, often as deposits. Biochars can persist for long periods of time in the soil at various depths, typically thousands of years. The most common example is charcoal, derived from wood. Similarly, the Terra Preta soils of the Amazon Basin are one of the more widely known examples of biochar.

In recent years, considerable research has focused on biochar, its nature, and its properties to explore its potential benefits and negative impacts, particularly for applying to agricultural fields as amendments. This publication provides a general description of biochar, as well as technical details, benefits, and disadvantages of biochar for agricultural and environmental uses. The intended audiences for this factsheet are agricultural producers, crop professionals, state agencies, researchers, resource conservationists, Extension educators, high school teachers, students, and the general public.

\section{How Are Biochars Made?}

The benefical effects of biochar were discovered more than 2,000 years ago when the "slash-and-burn" agricultural method was in practice. Natural forest fires and historical cultural practices also resulted in the formation of biochars that are stable over thousands of years as soil deposits. There are numerous types of biochars depending on the original material from which they are derived. Each specific type of carbon-rich material results in a very specific and different type of biochar, reflecting the physical and chemical properties of the parent material. For example, biochars derived from different types of trees (wood) or plant species result in different types of biochars.

Biochar can also be created artificially. Typically, biochars are formed by heating biomass or wastes containing C through a process called pyrolysis. Pyrolysis involves thermal and chemical decomposition of biomass, in limited or zero supply of oxygen. Biochar is typically produced at temperatures between $300^{\circ} \mathrm{C}-1000^{\circ} \mathrm{C}$ (Glaser et al. 2001). The absence of oxygen prevents complete combustion of the material and the amount of biochar and other by-products obtained depends on the temperature. Lower temperatures $\left(300^{\circ} \mathrm{C}-600^{\circ} \mathrm{C}\right)$ yield more solid char material and temperatures above $700^{\circ} \mathrm{C}$ result in more liquid/gas components. Typical waste-to-energy projects involve pyrolysis at high temperatures and result in gasification of biomass yielding approximately $20 \%$ Syngas, a combustible gas used in internal combustion engines, composed of primarily carbon monoxide and hydrogen, along with bio-oil and biochar.

Various types of biomass have been used on a commercial scale for biochar production successfully, including agricultural and forestry by-products (such as straw, nut shells, rice hulls, wood chips, wood pellets, tree bark, and switch grass), industrial by-products (such as bagasse from

1. This document is SL383, one of a series of the Department of Soil and Water Science, UF/IFAS Extension. Original publication date: August 2013. Please visit the EDIS website at http://edis.ifas.ufl.edu.

2. Rao Mylavarapu, professor, Vimala Nair, research professor, Department of Soil and Water Science, and Kelly Morgan, associate professor, Southwest Florida Research and Education Center, Immokalee, FL; UF/IFAS Extension, Gainesville, FL 32611. 
the sugarcane industry, paper sludge, and pulp), animal wastes (such as chicken litter, dairy and swine manure), and sewage sludge. Converting biomass to biochars offers an excellent method for reducing waste and using these byproducts. Biochars can also be engineered to have specific physical and chemical properties by selecting appropriate feedstock and pyrolyisis conditions. Engineering biochars to have specific properties can increase the ability of biochars to serve as a soil amendment and/or as a low-cost sorbent for organic and inorganic pollutants (Chen, Chen, and Lv 2011; Novak et al. 2009).

\section{Uses of Biochars}

When applied as soil amendments, biochars are known to improve soil physical and chemical properties, such as increasing soil fertility and productivity. Current research is focused on understanding the physics and chemistry of soil-applied biochars by studying the methods and rates of applications and documenting benefits for use as agricultural amendments. Many recent studies are also focusing on broader impacts of biochars, such as the potential for climate change mitigation at a global scale. These studies are evaluating increases in soil carbon storage at regional scales. An estimated 2.2 gigatons of $\mathrm{C}$ can be stored in the soil by 2050 using biochar conversion technologies, according to the International Biochar Initiative (http://www. biochar-international.org/biochar). Other benefits from amending soils with biochars include minimizing nitrous oxide and methane emissions, minimizing leaching of nutrients to groundwater, and reducing contaminant levels in soils, among others.

\section{Impacts on Agriculture}

The characteristics of biochars and its potential benefits when applied to the land are both influenced by the specific material of the biochar and the processing technique used. Biochars can retain applied fertilizer and nutrients and release them to agronomic crops over time. Biochars' ability to retain water and nutrients in the surface soil horizons for long periods benefits agriculture by reducing nutrients leaching from the crop root zone, potentially improving crop yields, and reducing fertilizer requirements. Thus, using biochars in production agriculture should improve yields and reduce negative impacts on the environment. A distinction between biochars and composts should be made here for clarity. Biochars differ from composts commonly added to soils for agricultural production in that compost is a direct source of nutrients through further decomposition of organic materials. However, biochars do not decompose with time and so additional applications should not be necessary.

A recent review of biochar articles by Spokas et al. (2012) concluded that while application of biochars can lead to positive results in agricultural production, there have been some reports of no crop yield benefits (Schnell et al. 2012) or even negative yield responses (Lentz and Ippolito 2012). Reported low yields could be because of reduced nutrient release for plant uptake, application of biochar on fertile soils, or a low rate of biochar application. High yields observed in some cases of biochar application could not be easily explained, but might depend on biochar properties, the soil fertility status, and the agronomic crop under consideration. Ippolito, Laird, and Busscher (2012) pointed out that most recent research on biochar has been conducted on highly weathered and infertile soils where benefits of biochar application were often noted. UF/IFAS researchers are working on determining benefits of biochars on sandy soils of Florida with low fertility and documenting any improvements in crop growth and yield.

\section{Impacts on the Environment}

As discussed earlier, biochars can have benefits for waste reduction, energy production, $\mathrm{C}$-sequestration, and soil fertility. Also, different biochars (derived from a variety of feedstocks) have been recognized as highly efficient lowcost sorbents for various pollutants in the environment. Application of biochars to soils has been investigated at the laboratory and field scale as an in-situ remediation strategy for both organic and inorganic contaminants to determine their ability to increase the sorption capacity of varying soils and sediments. For example, Chun et al. (2004) reported biochars generated by pyrolyzing wheat residues at temperatures ranging from $300^{\circ} \mathrm{C}$ to $700^{\circ} \mathrm{C}$ removed benzene and nitrobenzene (organic contaminants) from wastewater. Similarly, biochars produced from greenwaste (a mixture of maple, elm, and oak woodchips and bark) removed atrazine and simazine from aqueous solution (Zheng et al. 2010). Pine needle-derived biochar removed naphthalene, nitrobenzene, and $\mathrm{m}$-dinitrobenzene from water (Chen, Zhou, and Zhu 2008). Straw-derived biochar was found to be an excellent, cost-effective substitute for activated carbon to remove dyes (reactive brilliant blue and rhodamine B) from wastewater (Qiu et al. 2009). Biochar derived from dairy manures (pyrolysis from $200^{\circ} \mathrm{C}$ to $300^{\circ} \mathrm{C}$ ) also removed substantial amounts of atrazine from wastewater (Uchimiya et al. 2010).

In addition to removing organic contaminants, biochars have also been shown to remove metal contaminants 
and nutrients from wastewater and soil. Cao et al. (2009) investigated the sorption capacities of biochars produced by the pyrolysis of dairy manures at low temperatures $\left(200^{\circ} \mathrm{C}\right.$ and $\left.350^{\circ} \mathrm{C}\right)$. They found that the biochar was six times more effective in removing lead $(\mathrm{Pb})$ from wastewater than a commercial activated carbon. Broiler litter manure biochar enhanced the immobilization of heavy metals including cadmium $(\mathrm{Cd})$, copper $(\mathrm{Cu})$, nickel $(\mathrm{Ni})$, and $\mathrm{Pb}$ in soil and water (Uchimiya et al. 2011). Yao et al. (2011) reported biochar derived from anaerobically digested sugar beet tailings (DSTC) removed $73 \%$ of phosphate from the tested water. Also, magnetic biochars were found to be effective at removing hydrophobic organic contaminants and phosphate from solution simultaneously (Chen, Chen, and Lv 2011). These results show the potential of biochars to minimize nutrient leaching in agricultural fields.

\section{Summary}

Biochars are obtained through pyrolyzing biomass at temperatures above $300^{\circ} \mathrm{C}$ in the absence of oxygen. Degraded, dry lands and soils with poor fertility and low organic matter can immensely benefit from biochar amendments. In documented cases, biochars have improved nutrient and water-holding capacities, increased fertility and productivity, and improved crop management efficiency. Additional benefits come from biochar's ability to sorb contaminants, including inorganic and organic pollutants in the soil and leaching waters, thus improving soil and water quality. Using biochar as a soil amendment can help sequester stable carbon in soils and combat climate change. However, responses to biochars may depend on the type of biochar used and the specific characteristics of that biochar. Because biochar characteristics determine its suitability for specific agronomic or environmental purposes, biochar production must be tailored to address such specific needs.

\section{References}

Cao, X., L. Ma, B. Gao, and W. Harris. 2009. "Dairy-Manure Derived Biochar Effectively Sorbs Lead and Atrazine." Environmental Science and Technology 43(9): 3285-3291.

Chen, B., D. Zhou, and L. Zhu. 2008. “Transitional Adsorption and Partition of Nonpolar and Polar Aromatic Contaminants by Biochars of Pine Needles with Different Pyrolytic Temperatures." Environmental Science and Technology 42(14): 5137-5143.

Chen, B., Z. Chen, and S. Lv. 2011. "A Novel Magnetic Biochar Efficiently Sorbs Organic Pollutants and Phosphate." Bioresource Technology 102(2): 716-723.
Chun, Y., G. Sheng, C. T. Chiou, and B. Xing. 2004. “Compositions and Sorptive Properties of Crop Residue-Derived Chars." Environmental Science and Technology 38(17): 4649-4655.

Glaser, B., L. Haumaier, G. Guggenberger, and W. Zech. 2001. "The 'Terra Preta' Phenomenon: A Model for Sustainable Agriculture in the Humid Tropics." Naturwissenschaften 88(1): 37-41.

Ippolito, J. A., D. A. Laird, and W. A. Busscher. 2012. “Environmental Benefits of Biochar". Journal of Environmental Quality 41(4): 967-972

Lentz, R. D., and J. A. Ippolito. 2012. "Biochar and Manure Affect Calcareous Soil and Corn Silage Nutrient Concentrations and Uptake." Journal of Environmental Quality 41(4): 1033-1043.

Novak, J. M., I. Lima, B. Xing, J. W. Gaskin, C. Steiner, K. C. Das, M. Ahmedna, D. Rehrah, D.W. Watts, W. J. Busscher, et al. 2009. "Characterization of Designer Biochar Produced at Different Temperatures and Their Effects on a Loamy Sand." Annals of Environmental Science 3(1): 2.

Qiu, Y., Z. Zheng, Z. Zhou, and G. D. Sheng. 2009. “Effectiveness and Mechanisms of Dye Adsorption on a StrawBased Biochar." Bioresource Technology 100(21): 5348-5351.

Schnell, R. W., D. M. Vietor, T. L. Provin, C. L. Munster, and S. Capareda. 2012. "Capacity of Biochar Application to Maintain Energy Crop Productivity: Soil Chemistry, Sorghum Growth, and Runoff Water Quality Effects." Journal of Environmental Quality 41(4): 1044-1051.

Spokas, K. A., K. B. Cantrell, J. M. Novak, D. A. Archer, J. A. Ippolito, H. P. Collins, A. A. Boateng, I. M. Lima, M. C. Lamb, A. J. McAloon, R. D. Lentz, and K. A. Nichols. 2012. "Biochar: A Synthesis of Its Agronomic Impact Beyond Carbon Sequestration." Journal of Environmental Quality 41(4): 973-989.

Uchimiya, M., I. M. Lima, K. Thomas Klasson, S. C. Chang, L. H. Wartelle, and J. E. Rodgers. 2010. "Immobilization of Heavy Metal Ions (CuII, CdII, NiII, and PbII) by Broiler Litter-Derived Biochars in Water and Soil." Journal of Agricultural and Food Chemistry 58(9): 5538-5544.

Uchimiya, M., K. T. Klasson, L. H. Wartelle, and I. M. Lima. 2011. "Influence of Soil Properties on Heavy Metal Sequestration by Biochar Amendment: 1. Copper Sorption 
Isotherms and the Release of Cations." Chemosphere 82(10): 1431-1437.

Yao, Y., B. Gao, M. Inyang, A. R. Zimmerman, X. Cao, P. Pullammanappallil, and L. Yang. 2011. "Biochar Derived from Anaerobically Digested Sugar Beet Tailings: Characterization and Phosphate Removal Potential." Bioresource Technology 102(10): 6273-6278.

Zheng, W., M. Guo, T. Chow, D. N. Bennett, and N. Rajagopalan. 2010. "Sorption Properties of Greenwaste Biochar for Two Triazine Pesticides.” Journal of Hazardous Materials 181(1-3): 121-126. 